\title{
GUIA DE CUIDADOS EM TERAPIA INTRAVENOSA PERIFÉRICA NEONATAL: UMA CONSTRUÇÃO COLETIVA DA EQUIPE DE ENFERMAGEM $^{1}$
}

\section{CARE GUIDE FOR NEONATAL PERIPHERAL INTRAVENOUS THERAPY: A COLLECTIVE CONSTRUCTION OF NURSING TEAM}

\author{
GUÍA DE CUIDADOS EN TERAPIA INTRAVENOSA PERIFÉRICA \\ NEONATAL: UNA CONSTRUCCIÓN COLECTIVA DEL EQUIPO DE \\ ENFERMERÍA
}

\author{
Karine Baretta Toninelo Vieira* \\ Roberta COSTA ${ }^{* *}$
}

\begin{abstract}
RESUMO
Objetivo: Construir um Guia de cuidados em terapia intravenosa periférica com a equipe de enfermagem de uma unidade de terapia intensiva neonatal. Foi realizado no setor neonatal de uma maternidade escola que é referência em gestação de alto risco e cuidados intensivos neonatais no sul do Brasil. Método: Pesquisa convergente assistencial. Participaram do estudo 26 membros da equipe de enfermagem, sendo 7 enfermeiras e 19 técnicos de enfermagem. A coleta de dados ocorreu em quatro momentos distintos através da aplicação de questionário com perguntas abertas, espaços de reflexão, revisão integrativa sobre o tema e encontros no local da assistência. Resultados: Foi elaborado um Guia que integrou o conjunto de ações que direcionam a prática dos cuidados de enfermagem relacionados ao preparo, inserção e manutenção da terapia intravenosa periférica. Conclusão: Esta construção coletiva permitiu aos profissionais de enfermagem a reflexão sobre a sua realidade, motivando a mudança na sua forma de agir e pensar, favorecendo assim a melhoria da assistência prestada, bem como a garantia da segurança durante a execução do procedimento.
\end{abstract}

Palavras chave: Cuidados de enfermagem, cateterismo periférico, recém-nascido, neonatologia, guia.

\begin{abstract}
Objective: To develop a care guide for neonatal peripheral intravenous therapy with nurses of a neonatal intensive care unit. This was carried out in in the Department of Neonatology of a maternity school considered a model for high-risk pregnancy and neonatal intensive care in the south of Brazil. Methods: Convergent-care research. The study involved 26 members of a nursing team, 7 nurses and 19 nurse technicians. Data were

\footnotetext{
${ }^{1}$ Manuscrito extraído da Dissertação de Mestrado "Cuidados de enfermagem em terapia intravenosa periférica em unidade de tratamento intensivo neonatal: uma construção coletiva” apresentada ao Programa de Pós-Graduação Gestão do Cuidado em Enfermagem - Mestrado Profissional (MPENF) da Universidade Federal de Santa Catarina (UFSC).

* Mestre Profissional em Gestão do Cuidado em Enfermagem. Enfermeira da unidade de terapia intensiva neonatal da Maternidade Carmela Dutra. Membro do Grupo de Pesquisa em Enfermagem na Saúde da Mulher e do Recém-nascido (GRUPESMUR).Santa Catarina, Brasil.E-mail: karine_toninelo@hotmail.com

${ }^{* *}$ Doutora em Enfermagem, Professora do Departamento de Enfermagem e do MPENF/UFSC, Pesquisadora do GRUPESMUR. Orientadora do Estudo. Santa Catarina, Brasil.E-mail: roberta.costa@ufsc.br
} 
collected at four different stages through a questionnaire with open questions, opportunities for reflection, integrative review and on-site care meetings. Results: A guide including a set of actions related to nursing practice in the preparation, application and maintenance of peripheral intravenous therapy was developed. Conclusion: This collective construction allowed nurses to reflect on their reality, promote change in their way of acting and thinking, thus improving care provision and safety during a procedure.

Key words: Nursing care, peripheral catheterization, newborn, neonatology, guide.

\section{RESUMEN}

Objetivo: Construir una guía de cuidados para la terapia intravenosa periférica, con el personal de enfermería de una unidad de cuidado intensivo neonatal. Se realizó en el Departamento de Neonatología de una escuela de maternidad que es referencia en el embarazo de alto riesgo y de cuidados intensivos neonatales en el sur de Brasil. Material y método: Investigación convergente asistencial. En el estudio participaron 26 integrantes del equipo de enfermería: 7 enfermeras y 19 técnicos de enfermería. Los datos fueron recolectados en cuatro etapas distintas a través de un cuestionario con preguntas abiertas, espacios de reflexión, revisión integradora sobre el tema y reuniones sobre asistencia in situ. Resultados: Se elaboró una Guía que incluyó un conjunto de acciones que guían la práctica de cuidados de enfermería relacionados con la preparación, la inserción y el mantenimiento de la terapia intravenosa periférica. Conclusión: Esta construcción colectiva permitió a las enfermeras reflexionar sobre su realidad, motivar el cambio en su forma de actuar y de pensar, lo que favorece la mejora de la atención recibida, así como garantiza la seguridad durante la ejecución de un procedimiento.

Palabras clave: Cuidados de enfermería, cateterización periférica, recién nacido, nonatología, guía.

Fecha recepción: 18/09/14 Fecha aceptación: 03/11/15

\section{INTRODUÇÃO}

A sobrevivência dos Recém-Nascidos (RN) está diretamente ligada ao sucesso da Terapia Intravenosa (TI), uma vez que precisam de medicamentos endovenosos e nutrição parenteral muitas vezes por longo período, no entanto, esta terapia gera dor, estresse e risco de complicações graves $(1,2)$. Considerando todos os cuidados especializados prestados aos neonatos, a TI é um dos desafios e preocupações enfrentadas pela enfermagem (3).

A TI neonatal é um procedimento de difícil execução pela equipe de enfermagem, pois os RNs apresentam particularidades em sua fisiologia como: imaturidade da pele, limitação de rede venosa, instabilidade hemodinâmica, maior susceptibilidade a infecções, diminuição de tecido subcutâneo e sensibi- lidade aumentada à dor, sendo assim é importante que os profissionais de enfermagem reflitam criticamente acerca dos aspectos técnico-científico e ético-legais sobre este tema, com a finalidade de implantar novos modelos assistenciais baseados em conhecimento científico atualizado, contribuindo para um cuidado individualizado, seguro e humanizado (4).

A TI periférica requer avaliação criteriosa da rede venosa para a escolha do melhor local de punção e de uma técnica eficaz, permitindo a entrada de um dispositivo tecnológico diretamente na corrente sanguínea (5). Os profissionais de enfermagem necessitam adquirir competência técnica e científica em relação ao procedimento da punção venosa periférica, a fim de prestar assistência de enfermagem livre de danos e com qualidade (5). 
Assim, torna-se necessária a criação de espaços para os profissionais de enfermagem neonatal refletirem sobre as suas práticas diárias, expondo as dúvidas, os medos, as facilidades e as dificuldades relacionadas as experiências vividas no seu cotidiano. Esta reflexão permite que em conjunto os profissionais possam repensar sua práxis, obtendo não só aperfeiçoamento profissional como também exercendo sua cidadania, uma vez que realiza reflexão das suas atribuições (6).

A partir da reflexão, o profissional da equipe enfermagem pode elaborar instrumentos que assegurem uma padronização e sistematização da sua prática assistencial. Neste sentido, os Guias são utilizados como forma de orientações para as instituições de saúde desde a década de 1990, nos Estados Unidos. A partir deste momento, muitos profissionais de saúde iniciaram propostas de ações para o cuidado ou adaptações de orientações já existentes, trazendo a realidade do seu cenário de prática como base para esta criação. Estes Guias auxiliam os profissionais e promovem uma assistência baseada em conhecimento científico atualizado, trazendo mais segurança e qualidade ao cuidado prestado (7).

Para assegurar a eficácia da TI o enfermeiro deve elaborar rotinas fundamentadas cientificamente, em conjunto com a sua equipe de trabalho, garantindo desta forma a manutenção livre de iatrogenias para o RN (8). Refletir sobre essa problemática trouxeme a necessidade de discutir com a equipe a padronização dos cuidados em TI periférica em Unidade de Terapia Intensiva Neonatal (UTIN) para direcionar as ações dos profissionais da equipe de enfermagem envolvidos nesta terapia.

Ao buscar suporte na literatura sobre Guias ou Protocolos sobre TI periférica em recém-nascido constatamos que a produção científica neste tema é escassa, sendo que as publicações estão relacionadas principalmente ao paciente adulto e/ou a recomendações para prevenção de infecções da corrente sanguínea uma vez que este é o evento adverso mais frequente associado ao dispositivo intravascular (9-12).

Atuando como enfermeira de uma UTIN, observo que a prática da TI periférica é desenvolvida por todos os profissionais de enfermagem. Como a assistência é realizada de forma integral, o profissional responsável pelo $\mathrm{RN}$ é o primeiro a executar a técnica. $\mathrm{O}$ técnico de enfermagem é o profissional que mais realiza a técnica de punção venosa periférica e o enfermeiro é o responsavel pela supervisão da manutenção da TI. A avaliação do tipo de acesso venoso é realizada através das características clínicas do RN não levando em conta muitas vezes o tipo de droga utilizada e o tempo da terapia. Em relação a normativas existentes, na unidade existe um Procedimento Operacional Padrão (POP) que orienta a forma de realização da técnica, bem como, a maneira adequada de desinfecção das conexões conforme padronização da Comissão de Controle de Infecção Hospitalar (CCIH). No entanto, a equipe sente a necessidade de um direcionamento maior para esta prática.

Além das condições elucidadas anteriormente é importante referir também que na prática observo desinformação da equipe com relação ao preparo, inserção e manutenção da TI, como: escolha incorreta da veia a ser puncionda por parte de alguns profissionais quando o RN é pré-termo ou possui fragilidade venosa; nem sempre se elege o profissional mais habilitado do plantão para iniciar a tentativa de punção nesse tipo de clientela; a realização do procedimento é feita individualmente em alguns momentos; não há um limite de tentativas de punção por profissionais; falta de avaliação contínua por parte da equipe em relação a permeabilidade do acesso e a prevenção de complicações.

Neste contexto, o objetivo deste estudo foi construir um Guia de cuidados em TI periférica com a equipe de enfermagem de uma UTIN. 


\section{MÉTODO}

Trata-se de uma Pesquisa Convergente Assistencial (PCA), que tem o intuito de solucionar ou minimizar os problemas que envolvem o cuidado, gerar mudanças e inovações na prática de cuidar. Permite que a enfermeira encontre formas de auxiliar a equipe de enfermagem a promoverem-se enquanto sujeitos deste caminhar (13). Este tipo de investigação pressupõe que o pesquisador esteja imerso na prática possibilitando o despertar para uma prática reflexiva que permite ao enfermeiro propor modos de cuidado aderentes à realidade concreta de sua prática, além de favorecer a avaliação dos resultados de sua ação (14).

No desenvolvimento da PCA, optamos por utilizar como referencial algumas ideias da metodologia problematizadora de Paulo Freire, em função da sua abordagem coletiva, reflexiva e dialógica. Durante o processo dialógico coletivo, os sujeitos se encontram na busca de caminhos de transformação da sua realidade, permeados pelo processo de ação-reflexão-ação e pela possibilidade de criar e recriar (15).

O estudo foi realizado na UTIN de uma Maternidade escola que é referência para gestação de alto risco e cuidados intensivos neonatais no estado de Santa Catarina, sul do Brasil. Participaram do estudo 26 profissionais da equipe de enfermagem, sendo 19 técnicos de enfermagem e 7 enfermeiros, que realizam cuidados de enfermagem em TI aos RNs internados. Os participantes foram informados sobre o objetivo do estudo e formas de coleta de dados adotadas durante a PCA e também assinaram o Termo de Consentimento Livre e Esclarecido quando aceitaram participar do estudo.

A pesquisa foi desenvolvida a partir de quatro estratégias diferentes de coleta de dados. A primeira foi realizada em outubro de 2012, com a aplicação de um questionário com perguntas abertas acerca do conheci- mento dos profissionais de enfermagem em relação a TI periférica, entregue aos participantes durante o seu horário de trabalho e os quais deveriam retornar à pesquisadora após terem sido respondido. A segunda foi desenvolvida através de dois encontros, nos meses de outubro a novembro de 2012, que possibilitaram ao grupo discutir sobre as ações que são desenvolvidas durante a TI no RN. Estes encontros proporcionaram aos profissionais a oportunidade de socializar suas ideias e experiências, refletirem sobre sua realidade, analisá-la de forma crítica, buscando compreendê-la e transformá-la. A terceira estratégia foi o desenvolvimento de uma revisão integrativa com o objetivo de conhecer a contribuição das pesquisas realizadas sobre TI periférica em RN dos últimos cinco anos (2009 - 2013), através de busca on line nas bases de dados Literatura Latino Americana e do Caribe em Ciências da Saúde (LILACS), Base de Dados da Enfermagem (BDENF) e Sistema Online de Busca e Análise de Literatura Médica (MEDLINE), sendo que 12 artigos foram incluídos no processo de análise por contemplarem os critérios de inclusão. A revisão da literatura foi realizada no intuito de possibilitar a tomada de decisões criteriosas embasadas pelas evidências atuais, além de incluir as novas tecnologias utilizadas na TI periférica. Na construção deste guia, utilizou-se como base a classificação das recomendações por nível de evidência do Center for Disease Control and Prevention-CDC:

- Categoria IA - Implementação fortemente recomendada e ampla sustentação em estudos experimentais, clínicos ou epidemiológicos bem desenhados.

- Categoria IB - Implementação fortemente recomendada, sustentada por alguns estudos experimentais, clínicos ou epidemiológicos, além de forte fundamentação teórica; ou então, uma prática aceita (p.ex., técnica asséptica) sustentada em evidências limitadas. 
- Categoria IC - Exigida por regulamentação, regras ou normas estaduais ou federais.

- Categoria II - Implementação sugerida, sustentada em estudos clínicos ou epidemiológicos sugestivos ou em fundamentação teórica. Questão não resolvida. Representa uma questão não resolvida na qual há evidências insuficientes ou ausência de consenso com relação à efetividade (9).

E por fim, foram realizados dois encontros durante as atividades assistenciais dos profissionais com o objetivo de refletir sobre os cuidados necessários para a construção do Guia de cuidados em TI periférica para RN. Estes encontros ocorreram nos meses de dezembro de 2013 e janeiro de 2014, em dias consecutivos e em diferentes plantões com o objetivo de possibilitar a participação de um maior número de profissionais. Durante os encontros, foi elaborada uma lista dos cuidados de enfermagem, fundamentação científica e justificativa, a partir das evidencias cientificas encontradas na literatura. Sendo que as pesquisadoras ficaram responsáveis por organizar a versão preliminar do Guia. Em seguida, esta versão ficou disponível no setor por 5 dias em um envelope identificado localizado no posto de enfermagem para que os profissionais pudessem apresentar suas contribuições com tranquilidade e sanar suas dúvidas. Após este período, foi elaborada a versão final do Guia de cuidados em TI periférica em UTIN conforme construção coletiva da equipe.

Cabe destacar que o processo de análise ocorreu concomitante ao processo investigativo, ou seja, ao final de cada etapa de coleta de dados, era efetuada uma análise detalhada do material com o propósito de auxiliar na etapa seguinte. Assim para análise dessa PCA, tomaram-se como base o consenso dos participantes do estudo sobre os cuidados desen- volvidos na prática e os achados da revisão integrativa. A análise dos dados envolveu os processos de apreensão, síntese e teorização, interpretando-os sob a luz da literatura tem por base as evidências científicas que resultaram na construção do Guia de cuidados em terapia intravenosa periférica neonatal.

A pesquisa obedeceu aos preceitos éticos da Resolução 466/12 do Conselho Nacional de saúde sobre pesquisas com seres humanos, sendo o projeto de pesquisa aprovado pelo Comitê de Ética em Pesquisa da Universidade Federal de Santa Catarina, sob protocolo n. 95.468 e pelo Comitê de Ética em Pesquisa da Instituição sob protocolo n. 99.352.

\section{RESULTADOS}

A elaboração de um Guia envolvendo a equipe permitiu aos profissionais a reflexão sobre a sua realidade, o seu cuidado e motivou a mudança na sua forma de agir e pensar no seu cotidiano, favorecendo assim a melhoria da assistência prestada, bem como a garantia da segurança durante a execução do procedimento.

O desenvolvimento desta investigação mostrou a necessidade de espaços para refletir sobre as nossas ações diárias, para socialização de ideias e experiências, para que possamos nos dar conta de que as mudanças são necessárias e imprescindíveis na prática assistencial.

Este Guia de cuidados integra o conjunto de ações, construído coletivamente, onde estão contemplados os principais cuidados de enfermagem e a justificativa científica para cada ação. Apresentamos a estrutura do Guia em três quadros, como um recurso didático que visa a facilitar os procedimentos propostos e seu nível de evidência, sendo agrupados em cuidados referentes ao preparo, inserção e manutenção da TI. 


\section{Quadro 1. Cuidados de enfermagem no Preparo do RN e do ambiente.}

\section{\begin{tabular}{|l|l}
\hline AÇÃO DE ENFERMAGEM e & JUSTIFICATIVA
\end{tabular} NİVEL DE EVIDÊNCIA}

Avaliar o tipo de dispositivo necessário para o RN. (IB)
A escolha do dispositivo periférico deve ser feita mediante a sua finalidade, com base no tempo de terapia, na osmolaridade da infusão, e nas condições do acesso venoso. Quando o RN apresenta peso de nascimento inferior a $1200 \mathrm{~g}$, centralização fetal, idade gestacional menor que 30 semanas, está em ventilação mecânica e tem indicação de uso de nutrição parenteral está indicado, conforme norma da Instituição, o cateterismo umbilical $(9-12,16)$.

Higienizar as mãos, durante 40 a $60 \mathrm{seg}$, com solução antisséptica degermante de clorexidine $2 \%$ primeira escolha e $4 \%$ segunda escolha. (IB)

A equipe de saúde executa suas atividades através das suas mãos, e a segurança do paciente é mantida quando ocorre a higienização das mãos rotineiramente (17).

A lavagem das mãos é a medida preventiva mais importante contra infecção (18), reduz as taxas de indicadores de infecção de corrente sanguínea (9). A higienização das mãos antecedendo o preparo do material resulta em uma TI segura (19).

O uso de solução antisséptica é recomendado antes da realização de procedimentos invasivos $(11,12,17-19)$.

A solução antisséptica degermante de Gluconato de clorexidina apresenta ação bactericida para cocos gram-positivos e bacilos gram-negativos, ação antiviral para vírus lipofílicos (influenza, citomegalovírus, herpes, HIV) e ação fungicida (18).

Falar suavemente com o RN antes do procedimento, observando as pistas fisiológicas e comportamentais. Caso a família esteja presente, deve-se orientá-la quanto a necessidade do procedimento sugerindo que a mesma acompanhe o procedimento. (IC)

Os cuidados com o RN devem ser modulados pelos seus sinais fisiológicos e comportamentais. Esta medida reduz o estresse e a dor do RN, favorecendo seu conforto, segurança e desenvolvimento (20).

A presença e a participação da família são consideradas uma prática fundamental no cuidado ao $\mathrm{RN}$, deve-se estabelecer uma relação de parcerias na qual as responsabilidades devem ser compartilhadas pelos pais e profissionais de saúde, promovendo a qualidade da assistência (21).

Aquecer o RN. (IB)

Realizar controle da dor através de medidas não farmacológicas, tais como: oferta de sacarose 2 minutos antes do procedimento (IB), enrolamento (IC), contato pele a pele (IB) e controle do ambiente (IC).
Quando o RN está adequadamente aquecido, proporciona-se maior vascularização (18).

O controle da dor favorece a redução dos estímulos estressores, reduzindo o consumo de energia, e contribuindo para a organização homeostática (20). Os profissionais que atuam em UTIN precisam realizar o seu cuidado baseado na prevenção e controle da dor, a fim de possibilitar o bem-estar do RN, impedindo que no decorrer de seu desenvolvimento surjam sequelas provenientes de procedimentos dolorosos realizados durante a internação nesta unidade (22).

Quando for realizado procedimento que desencadeia dores agudas como a punção venosa, a utilização de medidas não farmacológicas a exemplo das soluções adocicadas oral, sucção não nutritiva, contato pele a pele, dentre outros são favoráveis ao alivio e controle da dor (23). 
Continuação Quadro 1.

Preparar todo o material necessário em uma bandeja: abocath ${ }^{\circledR}$, extensor dupla via, seringa $1 \mathrm{ml}$ com cloreto de sódio $0,9 \%$, película transparente, esparadrapo, algodão com clorexidina alcoólica como primeira escolha e álcool $70 \%$ como segunda escolha, luva de procedimento. (IB)
Quando a equipe de enfermagem organiza o material necessário para a realização do procedimento anteriormente a sua execução, esta proporciona uma técnica segura, ágil e sem risco de iatrogênias, bem com reduz os estímulos estressores e dolorosos $(18,19)$.

\section{Quadro 2. Cuidado de enfermagem durante a Inserção da TI.}

\section{\begin{tabular}{|l|l}
\hline AÇÃO DE ENFERMAGEM e & JUSTIFICATIVA
\end{tabular} NİVEL DE EVIDÊNCIA}

Realizar os procedimentos em dupla, podendo ser solicitado ajuda para a família. (IC)

Selecionar o sítio de inserção dando preferência para as veias das extremidades. (IB)

Utilizar equipamento que favoreça a visualização das veias como o uso de ultrassom (IB)

Utilizar luvas não estéreis para a inserção do cateter venoso periférico. (IA)

Realizar fricção da pele com gluconato de clorexidina $0,5 \%$, tempo de friç̧ão 30 segundos no sentido unidirecional; e esperar secar espontaneamente. (IA) crianças (22).
Durante a realização de procedimentos é prudente que uma pessoa realize suporte contínuo no RN (podendo ser os pais) (18). Preferencialmente os profissionais mais experientes devem executar o procedimento de punção venosa e que este tenha auxilio de outro colega, a fim de adequação dos procedimentos técnicos e diminuição dos estímulos estressantes $(9-12,18,20)$.

A escolha do melhor local para se puncionar é baseada em aspectos fisiológicos, neste sentido a escolha da veia é iniciada sempre pelas extremidades, para que seja preservada as veias distais, caso seja necessário novas punções $(9-12,16,19)$.

O uso deste dispositivo reduz o numero de tentativas de punções venosas periféricas e otimiza o tempo de realização do procedimento em

Usar Equipamento de Proteção Individual (EPI's) na realização do procedimento minimiza risco para a saúde do trabalhador (10-12).

A solução antisséptica degermante de gluconato de clorexidina apresenta ação bactericida para cocos gram-positivos e bacilos gram-negativos, ação anti viral para vírus lipofílicos (influenza, citomegalovírus, herpes, HIV) e ação fungicida (18).

O sítio de inserção do dispositivo intravenoso periférico não deverá ser tocado após a aplicação do antisséptico, salvo quando a técnica asséptica for mantida. A remoção dos pêlos, quando necessária, deverá ser realizada com tricotomizador elétrico ou tesoura $(9-11,18)$. Entretanto, sugere-se cautela no uso desta técnica uma vez que, especialmente no caso de RN pré-termos, pode causar risco a integridade cutânea.

Após a seleção e assepsia da pele, o profissional auxiliar deve garrotear o membro com as suas mãos, tomando o cuidado para não exceder um minuto de garroteamento. (II)
A realização do garroteamento promove maior enchimento capilar, melhorando a visualização da veia (17).

Evitar o garroteamento excessivo e prolongado, pois este acarreta em aumento da pressão no interior dos vasos podendo levar ao rompimento da veia e perda do local puncionado (18). 


\begin{tabular}{|c|c|}
\hline $\begin{array}{l}\text { O profissional executor deverá es- } \\
\text { ticar a pele com seus dedos e pun- } \\
\text { cionar a veia com o bisel voltado } \\
\text { para cima. Inserindo a agulha na } \\
\text { pele num ângulo de } 45^{\circ} \text {. } \\
\text { A inserção deverá ser feita } 1 \mathrm{~cm} \\
\text { antes do local a ser puncionado. } \\
\text { No surgimento de refluxo de san- } \\
\text { gue, retirar o garrote. (II) }\end{array}$ & $\begin{array}{l}\text { A inserção do dispositivo intravenoso periférico deve ser feita } 1 \mathrm{~cm} \text { an- } \\
\text { tes do local a ser puncionado e deve ser inserido com um ângulo de } 45^{\circ} \\
\text { para evitar a transfixação e o mal posicionamento da agulha }(18,19) \text {. }\end{array}$ \\
\hline $\begin{array}{l}\text { Quando observar o retorno veno- } \\
\text { so (refluxo), introduzir o cateter } \\
\text { adequadamente dentro da veia e ir } \\
\text { gradativamente retirando a agulha } \\
\text { guia. Conectar o extensor dupla } \\
\text { via e a seringa de } 1 \mathrm{ml} \text { já preenchi- } \\
\text { da com cloreto de sódio } 0,9 \% \text {. (II) }\end{array}$ & $\begin{array}{l}\text { Acessos vasculares devem ter sua permeabilidade mantida com cloreto } \\
\text { de sódio } 0,9 \% \text { antes e após o uso para promover e manter o fluxo, além } \\
\text { de prevenir a mistura de medicamentos e soluções }(9,10) \text {. }\end{array}$ \\
\hline $\begin{array}{l}\text { Fixar o cateter na pele, com cober- } \\
\text { tura transparente que possibilite a } \\
\text { visibilidade do local de inserção. } \\
\text { (IA) }\end{array}$ & $\begin{array}{l}\text { A cobertura tem por finalidade a proteção do sitio de inserção, dimi- } \\
\text { nuindo o risco á infecções e fixando o dispositivo de maneira que este } \\
\text { não possa se movimentar. } \\
\text { A cobertura deverá ser trocada imediatamente na presença de sujidade, } \\
\text { ou suspeita de contaminação e quando úmida ou solta e não sendo } \\
\text { trocada com datas pré-fixadas }(10,16) \text {. }\end{array}$ \\
\hline $\begin{array}{l}\text { Identificar o acesso venoso com a } \\
\text { data e o nome do profissional que } \\
\text { executou o procedimento. (II) }\end{array}$ & $\begin{array}{l}\text { A identificação do acesso possibilita o acompanhamento do tempo de } \\
\text { uso de cateter, e complicações relacionadas ao dispositivo, bem como o } \\
\text { planejamento de ações envolvendo a TI, no sentido de manter a segu- } \\
\text { rança do procedimento (19). }\end{array}$ \\
\hline $\begin{array}{l}\text { Não se deve exceder um número } \\
\text { máximo de } 5 \text { tentativas durante o } \\
\text { procedimento. (II) }\end{array}$ & $\begin{array}{l}\text { Um estudo em UTIN, na cidade de Fortaleza, constatou que o excesso } \\
\text { de manuseio interfere no bem estar do RN, pois durante os manuseios } \\
\text { eles apresentaram de oito a nove respostas fisiológicas e comportamen- } \\
\text { tais diferentes (24). Um estudo do Chile sugere que o número máximo } \\
\text { de tentativas de punção por profissional seja até três em caso de insu- } \\
\text { cesso solicite a outro profissional a tentativa (25). Cabe destacar que } \\
\text { muito mais importante do que um limite numérico para as tentativas } \\
\text { de punção, será avaliar as respostas comportamentais do RN frente ao } \\
\text { estímulo doloroso, utilizado sempre esta avaliação como definição para } \\
\text { interromper o procedimento e aguardar a estabilidade do RN (18). }\end{array}$ \\
\hline
\end{tabular}

Quadro 3. Cuidados de Enfermagem na Manutenção da TI.

\begin{tabular}{|l|l|}
\hline AÇÃO DE ENFERMAGEM e & JUSTIFICATIVA \\
NİVEL DE EVIDÊNCIA & \\
\hline $\begin{array}{l}\text { Realizar higienização das mãos } \\
\text { durante } 40 \text { a } 60 \text { seg, antes e após }\end{array}$ & $\begin{array}{l}\text { A lavagem das mãos é a medida preventiva mais importante contra in- } \\
\text { fecção }(11,12,18) \text {, reduz as taxas de indicadores de infecção de corren- } \\
\text { a manipulação do acesso veno- } \\
\text { so periférico com clorexidine } 4 \% \\
\text { primeira escolha e álcool gel } 70 \% \\
\text { como segunda escolha. (IA) }\end{array}$ \\
\hline
\end{tabular}


Continuação Quadro 3.

\begin{tabular}{|c|c|}
\hline $\begin{array}{l}\text { Avaliar o sítio de inserção diaria- } \\
\text { mente, no mínimo a cada troca } \\
\text { de plantão. Devendo ser realizada } \\
\text { durante os cuidados de rotina ao } \\
\text { RN, por meio da palpação e da } \\
\text { inspeção. Usar também a escala de } \\
\text { estadiamento do tecido extravasa- } \\
\text { do da unidade. (II) }\end{array}$ & $\begin{array}{l}\text { Os cateteres em neonatologia devem permanecer até o final da terapia, } \\
\text { sendo retirado somente em casos de flebite ou extravasamento. A ob- } \\
\text { servação do sítio de inserção do dispositivo é uma importante medida } \\
\text { na redução do risco de infecção da corrente sanguínea }(9,10) \text {. }\end{array}$ \\
\hline $\begin{array}{l}\text { Realizar desinfecção das conexões, } \\
\text { injetor lateral e hub a cada mani- } \\
\text { pulação antes de serem acessados } \\
\text { com clorexedina alcóolica à } 4 \% \\
\text { como primeira escolha e álcool á } \\
70 \% \text { como segunda escolha por } \\
\text { meio da fricção rigorosa com no } \\
\text { mínimo cinco movimentos circu- } \\
\text { lares. (IA) }\end{array}$ & $\begin{array}{l}\text { Durante o manuseio do acesso vascular é necessário que a equipe de } \\
\text { saúde adote medidas e técnicas assépticas para evitar infeção da corren- } \\
\text { te sanguínea relacionada a cateter }(16,26) \text {. }\end{array}$ \\
\hline $\begin{array}{l}\text { As dânulas (torneirinhas) e os } \\
\text { conectores deverão ser trocadas } \\
\text { imediatamente quando houver } \\
\text { presença de coágulos, e de } 72 \mathrm{~h} \\
\text { caso permaneçam integras (IA), já } \\
\text { os extensores deverão ser trocados } \\
\text { cada } 12 \text { h e os protetores de cone } \\
\text { (tampinhas) a cada manipulação } \\
(14) \text {. }\end{array}$ & $\begin{array}{l}\text { É importante que a equipe identifique a data da troca das conexões } \\
\text { a fim de obter um planejamento para que o sistema tenha a troca no } \\
\text { tempo adequado e evite infecções }(9,10) \text {. }\end{array}$ \\
\hline $\begin{array}{l}\text { Realizar o Teste de permeabilidade } \\
\text { do acesso antes e após, injetando } \\
0,5 \mathrm{ml} \text { de SF } 0,9 \% \text { a avaliando o sí- } \\
\text { tio de inserção. (II) }\end{array}$ & $\begin{array}{l}\text { A permeabilidade do acesso deverá ser realizada com cloreto de sódio } \\
0,9 \% \text { antes e após o uso no intuído de conservar o fluxo e evitar a mis- } \\
\text { tura de medicamentos e soluções }(9,10) \text {. }\end{array}$ \\
\hline $\begin{array}{l}\text { Realizar banho de leito do } \mathrm{RN} \text { que } \\
\text { estiver com dispositivo venoso pe- } \\
\text { riférico. (IC) }\end{array}$ & $\begin{array}{l}\text { O banho do RN com dispositivo venoso periférico deverá ser no leito, a } \\
\text { fim evitar que o curativo molhe, suje ou perca a sua integridade, com o } \\
\text { intuito de evitar infecção da corrente sanguínea }(10-12,16) \text {. }\end{array}$ \\
\hline $\begin{array}{l}\text { Realizar a limpeza e desinfecção } \\
\text { da superfície dos equipamentos } \\
\text { utilizados durante a TI (IA) às } \\
\text { 08h00min, 14h00min e 20h00min } \\
\text { e na troca de paciente, utilizando } \\
\text { o ácido peracético como primeira } \\
\text { escolha e agua e sabão como se- } \\
\text { gunda escolha nas partes acrílicas } \\
\text { e álcool } 70 \% \text { nas partes metálicas, } \\
\text { conforme padronização da insti- } \\
\text { tuição (12). }\end{array}$ & $\begin{array}{l}\text { A limpeza dos equipamentos utilizados durante a TI é uma medida } \\
\text { adotada para prevenir infecções da corrente sanguínea (9-12). }\end{array}$ \\
\hline
\end{tabular}


Continuação Quadro 4.

\begin{tabular}{|c|c|}
\hline $\begin{array}{l}\text { Realizar a inspeção do material e } \\
\text { seu funcionamento diariamente e } \\
\text { quando houver evento adverso ou } \\
\text { queixa técnica durante a TI, o pro- } \\
\text { fissional da saúde do setor deve } \\
\text { realizar a comunicação por escrito } \\
\text { para o responsável pelo programa } \\
\text { Sentinela da Instituição. (IC) }\end{array}$ & $\begin{array}{l}\text { O profissional da saúde é responsável por fazer a notificação de evento } \\
\text { adverso ou queixa técnica durante a utilização de produtos para saúde, } \\
\text { através de comunicação por escrito ao programa Sentinela da Institui- } \\
\text { ção. A Instituição deverá notificar ao Sistema Nacional de Vigilância } \\
\text { Sanitária, bem como encaminhar parecer negativo a Secretaria Estadu- } \\
\text { al de Saúde de Santa Catarina (10). } \\
\text { O enfermeiro exerce papel fundamental para a diminuição dos riscos } \\
\text { de danos e eventos adversos, garantindo a segurança da assistência } \\
\text { prestada aos usuários mediante ao gerenciamento das ações realizadas } \\
\text { pela equipe de enfermagem (27). A qualidade do cuidado de enferma- } \\
\text { gem reflete a segurança da assistência ao paciente neonatal. }\end{array}$ \\
\hline
\end{tabular}

É oportuno informar que alguns cuidados mencionados pelos profissionais como: controle da dor, implantação de escala da dor e manejo no extravasamento, no decorrer desta PCA, durante o processo de construção do Guia estes cuidados também foram padronizados. Além disso, incluímos neste instrumento, cuidados indispensáveis à TI com o intuito de deixar esta proposta mais completa possível, tais como: rotina de troca das conexões, número máximo de tentativas por profissional, limpeza dos equipamentos e a inspeção do material e de seu funcionamento diariamente.

Esta pesquisa motivou também uma capacitação da $\mathrm{CCIH}$, em relação a medidas preventivas para diminuir infecção da corrente sanguínea, incluindo cuidados como: higienização das mãos, cuidados no preparo da pele, na inserção do cateter e na manutenção da Terapia.

\section{DISCUSSÃO E CONCLUSÃO}

A reflexão sobre os cuidados para a construção do Guia permitiu que a equipe de enfermagem aprimorasse seus conhecimentos técnicos em relação à TI periférica, tendo como foco de estudo o preparo, a inserção e a manutenção da TI, evitando desta forma a dor e o estresse desnecessário ao RN, contribuindo para a segurança do paciente neonatal, assim como reduzindo gastos provenientes do prolongamento de internação em consequência de complicações.

Cabe destacar que a PCA adquire maior importância pelo seu caráter metodológico de idas e vindas diante do saber-fazer assistencial. Neste movimento de proximidade e afastamento entre a pesquisa e a assistência, há trocas recíprocas de informações ao longo de ambos os processos: os dados da PCA influenciam a prática assistencial em transformação e as informações da prática dão respostas às indagações da pesquisa (28).

No que diz respeito à produção científica foi identificado, tanto a nível nacional quanto internacional, que a equipe de enfermagem é a principal responsável pela TI periférica e possui importante papel na execução deste procedimento, desde a escolha do tipo de acesso até a retirada do mesmo no término da terapia. Os principais temas abordados foram relacionados à escolha de veias, manejo das complicações em TI periférica, controle de infeção relacionado à troca do dispositivo e formas de identificar as veias de difícil punção na primeira tentativa.

A revisão integrativa apontou a necessidade de mais estudos relacionados a TI, principalmente em relação ao controle da dor durante o procedimento, bem como associados aos cuidados para manutenção de um ambiente terapêutico adequado ao RN.

$\mathrm{O}$ enfermeiro exerce papel fundamental para a diminuição destes riscos garantindo 
a segurança da assistência prestada aos usuários mediante o gerenciamento das ações realizadas pela equipe de enfermagem (27). Assim, é importante que a equipe de enfermagem introduza em sua prática assistencial ações que promovam um cuidado qualificado respeitando os princípios ético-legais da profissão.

Os espaços de reflexões favoreceram a socialização de conhecimentos, fortalecendo o potencial dos envolvidos, possibilitando negociações e parcerias, e o processo de ação-reflexão e ação, propostos por Freire (15), oportunizando a criação e recriação de saberes, transformando e inovando o cuidado.

Esta investigação revelou que, ao padronizarmos as ações de enfermagem de forma coletiva, possibilitamos que os profissionais da equipe sintam-se comprometidos e responsáveis em repensar sua prática e transformar a realidade.

As discussões originadas durante a elaboração deste Guia trouxeram para o grupo troca de experiências e momentos de integração, alegria, entrosamento e envolvimento, bem como evidenciaram através da reflexão coletiva a necessidade de mudança na prática assistencial relacionada a TI na UTIN, uma vez que no dia a dia percebemos divergência de atitudes na prática.

Espera-se que esta pesquisa traga contribuições para os profissionais de enfermagem no sentido de direcionar as ações de cuidados em TI, além de estimular a realização de novas pesquisas para a implantação de instrumentos similares em outras realidades, no sentido de aprimorar e instrumentalizar a enfermagem neonatal no cuidado ao RN internado em UTIN.

\section{REFERÊNCIAS}

1. Menezes SO, Gomes MASM, Filho FL. Manejo do acesso vascular em recémnascidos de muito baixo peso ao nascer em unidades públicas neonatais do município do Rio de Janeiro. Revista Pesquisa e Saúde. 2013; 14(1): 11-15.

2. Rodrigues EC, Cunha SR, Gomes R. Perdeu a veia: significados da prática da terapia intravenosa na unidade de terapia intensiva neonatal. Cien Saude Colet. 2012; 17(4): 989-999.

3. Rovaris MJPH. Recém-nascido submetido ao Cateter Central de Inserção Periférica: a experiência da família e as contribuições da enfermeira. [Dissertação de Mestrado]. [Florianópolis]: Universidade Federal de Santa Catarina; 2010. 302 f.

4. Cardoso JMRM, Rodrigues EC, Rodrigues BMRD, Pacheco STA, Faria JCO. Escolha de veias periféricas para terapia intravenosa em recém-nascidos pela equipe de enfermagem. Revista RENE. 2011. 12(2): 365-375.

5. Modes PSSA, Gaíva MAM, Rosa MKO, Granjeiro CF. Cuidados de enfermagem nas complicações da punção venosa periférica em recém-nascidos. Revista RENE. 2011; 12(2): 324-332.

6. Steffens AP, Gelbcke FL. Uma prática educativa com profissionais de enfermagem que sofreram um acidente de trabalho com perfuro-cortantes. Scire Salutis. 2011; 1(1): 5-14.

7. Robertson J. Guide to the Development of Clinical Guias for Nurse Practitioners [Internet].Western Australia: Office of the chief nursing officer. Jun 2007 [citado 16 out. 2013]. Disponível em: http:// www.nursing.health.wa.gov.au/.../np/ Guide_to_the_development_of_clinical _guidelines.pdf

8. Santos LM, Holtz TRG, Santana DM, Lopes DM, Santos, LFN, Santana RCB. Critérios para fixação de acessos venosos periféricos em recém-nascidos prematuros. J Nurs UFPE on line [Internet]. 2013 [citado16 out. 2013]; 5(1): 3238-50. Disponível em: http://www.seer.unirio. br/index.php/cuidadofundamental/article/view/1877/pdf_681 
9. O'Grady N, Alexander M, Burns L, Dellinger EP, Garland J, Heard SO et al. Guidelines for the Prevention of Intravascular Catheter-Related Infections, 2011 [Internet]. Atlanta, GA: Centers for Disease Control and Prevention; 2011 [citado 27 set 2013]. 83 p. Disponível em: http://www.cdc.gov/hicpac/BSI/ BSI-guidelines-2011.html

10. Ministério da Saúde. Agência Nacional de Vigilância Sanitária. Orientações para prevenção de infecção primária de corrente sanguínea. Brasilia: Unidade de Investigação e Prevenção das Infecções e dos Efeitos Adversos - UIPEA. Agência Nacional de Vigilância Sanitária; 2010.

11. Ministerio de Sanidad, Servicios Sociales e Igualdad. Guía de Práctica Clínica sobre Terapia Intravenosa con Dispositivos no Permanentes en Adultos. Sevilla: Agencia de Evaluación de Tecnologías Sanitarias de Andalucía. Consejería de Igualdad, Salud y Políticas Sociales - Junta de Andalucia; 2014. 177 p.

12. Caballero MCC (coord.). Actualización enfermera en accesos vasculares y terapia intravenosa. Asociación de Enfermería de Equipos de Terapia Intravenosa. Madrid: Difusión Avances de Enfermería; 2008. $235 \mathrm{p}$.

13. Trentini M, Paim L. Pesquisa convergente-assistencial: um desenho que une o saber fazer e o saber pensar na prática assistencial em saúde-enfermagem. 2 da ed. Florianópolis: Insular; 2014.

14. Rocha PK, Prado ML do, Silva DMGV da. Pesquisa Convergente Assistencial: uso na elaboração de modelos de cuidado de enfermagem. Rev Bras Enferm. 2012; 65(6): 1019-1025.

15. Freire, P. Pedagogia da autonomia: saberes necessários à prática educativa. 39 ed. São Paulo: Paz e Terra; 2009.

16. Maternidade Carmela Dutra. Serviço de Controle de Infecção Hospitalar. Manual de orientações para procedimentos na UTI Neonatal. Florianópolis; 2012.
17. Agência Nacional de Vigilância Sanitária, Brasil. Segurança do Paciente em Serviços de Saúde: Higienização das Mãos. Brasília: Agência Nacional de Vigilância Sanitária; 2009.

18. Ministério da Saúde, Brasil. Secretaria de Atenção à Saúde. Departamento de Ações Programáticas e Estratégicas. Atenção à saúde do recém-nascido: guia para os profissionais de saúde. Brasília: Editora do Ministério da Saúde; 2011.

19. Alves LT, Machado PRF, Martins ERC. O acadêmico de enfermagem e a pratica de punção venosa periférica. Revista Saúde, Corpo, Ambiente e Cuidado. 2013; 1(1): 232-249.

20. Ministério da Saúde, Brasil. Secretaria de Atenção à Saúde. Departamento de Ações Programáticas Estratégicas. Atenção humanizada ao recém-nascido de baixo peso: Método Canguru. 2a ed. Brasília: Editora do Ministério da Saúde; 2011.

21. Costa R, Padilha MI. Percepção da equipe de saúde sobre à presença da família na UTI neonatal: resistência aos novos saberes. Rev enferm UERJ. 2011; 19(2): 231-5.

22. Presbytero R, Costa MLV, Santos RCS. Os enfermeiros da unidade neonatal frente ao recém-nascido com dor. Revista RENE. 2010; 11(1): 125-132.

23. Stevens B, McGrath P, Gibbins S, Beyene J, Breau L, Camfield C et al. Determining behavioural and physiological responses to pain in infants at risk for neurological impairment. Pain. 2007; 127(1): 94-102.

24. Magalhães FJ, Lima FET, Rolim KMC, Cardoso MVLML, Scherlock MSM, Albuquerque NLS. Respostas fisiológicas e comportamentais de recém-nascidos durante o manuseio em unidade de terapia intensiva neonatal. Revista RENE. 2011; 12(1): 136-143.

25. Lienqueo AR, Rivas E. Evaluación de protocolos de seguimiento de vías venosas periféricas: neonatología. Hospital Dr. Hernán Henríquez Aravena. Mayo- Junio 
de 2005. Cienc. enferm. 2008; $\operatorname{XIV(2):~}$ 47-53.

26. Mendonça KM, Neves HCC, Barbosa DFS, Souza ACS, Tipple AFV, Prado MA. Atuação da enfermagem na prevenção e controle de infecção de corrente sanguínea relacionada a cateter. Rev. enferm. UERJ. 2011; 19(2): 330-332.

27. Raduenz AC, Hoffmann P, Radunz V, Dal Sasso GT, Maliska IC, Marck PB. Cuida- dos de enfermagem e segurança do paciente: visualizando a organização, acondicionamento e distribuição de medicamentos com método de pesquisa. Rev Lat Am de Enfermagem. 2010; 18(10): 10451054.

28. Bonetti A, Silva DGV, Trentini M. O método da pesquisa convergente assistencial. Esc. Anna Nery. 2013; 17(1): 179-183. 